\title{
Regulation of Alternative Splicing by snoRNAs
}

\author{
S. KISHORE AND S. STAMM \\ University of Erlangen, Institute for Biochemistry, 91054 Erlangen, Germany
}

\begin{abstract}
The SNURF-SNRPN locus located on chromosome 15 is maternally imprinted and generates a large transcript containing at least 148 exons. Loss of the paternal allele causes Prader-Willi syndrome (PWS). The $3^{\prime}$ end of the transcript harbors several evolutionarily conserved $\mathrm{C} / \mathrm{D}$ box small nucleolar RNAs (snoRNAs) that are tissue-specifically expressed. With the exception of 47 copies of HBII-52 snoRNAs, none of the snoRNAs exhibit complementarity to known RNAs. Due to an 18-nucleotide sequence complementarity, HBII-52 can bind to the alternatively spliced exon $\mathrm{Vb}$ of the serotonin receptor 2C pre-mRNA, where it masks a splicing silencer, which results in alternative exon usage. This silencer can also be destroyed by RNA editing, which changes the amino acid sequence and appears to be independent of HBII-52. Lack of HBII-52 expression in individuals with PWS causes most likely a lack of the high-efficacy serotonin receptor, which could contribute to the disease. It is therefore possible that snoRNAs could act as versatile modulators of gene expression by modulating alternative splicing.
\end{abstract}

\section{ALTERNATIVE SPLICING}

One of the most striking results of the Human Genome Project was the demonstration that a surprisingly small number of genes generate a complex proteome. The estimated 20,000-25,000 human protein-coding genes could give rise to $100-150,000$ mRNA variants as estimated by comparison of expressed sequence tags. Array analysis shows that $74 \%$ of all human genes are alternatively spliced, and a detailed array-based analysis of chromosomes 22 and 21 suggests that every protein-coding gene could undergo alternative splicing (Kampa et al. 2004). Extreme examples illustrate the potential of alternative splicing: The human neurexin 3 gene could form 1728 transcripts (Missler and Sudhof 1998) and the Drosophila DSCAM gene could give rise to 38016 isoforms, which is larger than the number of genes in Drosophila (Celotto and Graveley 2001). Unlike promoter activity that predominantly regulates the abundance of transcripts, alternative splicing influences the structure of mRNAs and their encoded proteins. As a result, it influences binding properties, intracellular localization, enzymatic activity, protein stability, and posttranslational modification of numerous gene products (Stamm et al. 2005). Alternative splicing can indirectly regulate transcript abundance. About $25-35 \%$ of alternative exons introduce frameshifts or stop codons into the pre-mRNA (Stamm et al. 2000; Lewis et al. 2003). Since approximately $75 \%$ of these exons are predicted to be subject to nonsense-mediated decay, an estimated $18-25 \%$ of transcripts will be switched off by stop codons introduced by alternative splicing and nonsensemediated decay (Lewis et al. 2003). However, recent array analysis from mouse suggests that the actual number of regulated transcripts might be smaller than predicted (Pan et al. 2004). Finally, several proteins that regulate splice site usage shuttle between the nucleus and cytosol where they regulate translation (Sanford et al. 2004). The biological effects evoked by alternative splicing are diverse and range from a complete loss of function to subtle effects (Stamm et al. 2005). In summary, alternative splicing emerges as a key regulator for human gene expression.

\section{WIDESPREAD EXPRESSION OF SMALL RNAS IN THE HUMAN GENOME}

Recent tiling array data and detailed expression analysis showed that the expression data and gene structures collected in current databases are largely incomplete (Carninci et al. 2005). Numerous noncoding regions are transcribed into polyadenylated, stable RNAs, which are named TUF (transcript of unknown function). Within most previously well-characterized protein-coding genes, there are large numbers of noncoding transcribed fragments (transfrags) that could represent new exons or short RNAs of unknown sequence. A recent study of human gene expression using tiling arrays demonstrates that about $57 \%$ of the transfrags are not annotated in Genbank or EnsEMBL databases (Cheng et al. 2005). Transfrag sequences are not contained in previous databases since they often seem to derive from unstable RNAs, resulting in sequences that were discarded as fragmental cloning/library artifacts. Furthermore, they are not part of polyadenylated RNA and therefore escape poly $\left(\mathrm{A}^{+}\right)$ selection during library construction.

\section{C/D BOX SNORNAS}

C/D box snoRNAs are a group of short noncoding RNAs that have $\mathrm{C}$ and $\mathrm{D}$ boxes as characteristic sequence elements that help form the snoRNP. They reside in introns from which they are released during pre-mRNA processing of their host genes through nuclease action. A major function attributed to $\mathrm{C} / \mathrm{D}$ box snoRNAs was to guide $2^{\prime}$-O-methylation in ribosomal, transfer, and snRNAs. The guiding activity of snoRNAs is achieved by the formation of a specific RNA:RNA duplex between the snoRNA and its target. The snoRNAs contain a region, the antisense box, that exhibits sequence complementarity to its target and forms a short, transient double strand with the target. On the target RNA, the nucleotide base-pairing with the snoRNA nucleotide positioned 5 nucleotides upstream of the snoRNA D box is methylated on the 2'-O-hydroxyl group. Several snoRNAs show 
complementarity toward pre-rRNA, but the rRNA is not 2'-O-methylated at the predicted positions. It was therefore proposed that snoRNAs could also function as chaperons that help correct folding in rRNA processing (Steitz and Tycowski 1995). Recently, numerous C/D box snoRNAs were discovered that show no sequence complementarity to other RNAs, suggesting that C/D box snoRNAs might have a function other than 2'-O-methylation (Filipowicz and Pogacic 2002).

C/D box snoRNAs associate with proteins to form snoRNPs that contain four evolutionarily conserved, essential proteins: fibrillarin (Nop1p), Nop56p, Nop58p, and Snu13p/15.5 kD. Fibrillarin, which exhibits amino acid sequence motifs characteristic of SAM-dependent methyltransferases, is the likely snoRNA-guided modifying enzyme, as point mutations in the methylase-like domain disrupt all rRNA methylations. Snu13p, the yeast homolog of the mammalian $15.5-\mathrm{kD}$ protein, is found both in C/D box snoRNPs and in the U4/U6.U5 tri-snRNP (small nuclear ribonucleoprotein). It is likely that Snu13p/15.5 binds to an RNA structural motif (kink-turn) present in $\mathrm{U} 4$ snRNA that can also be formed by the $\mathrm{C}$ and $\mathrm{D}$ boxes of $\mathrm{C} / \mathrm{D}$ box snoRNAs. The occurrence of Snu13p/15.5 in U4 snRNP and C/D box snoRNPs suggests a common evolutionary origin and possibly functional similarities (Watkins et al. 2000).

\section{TISSUE-SPECIFIC SNORNAS DERIVED FROM THE SNURF-SNRPN LOCUS}

The sequencing of cDNA libraries enriched for small, nonpolyadenylated RNAs resulted in the identification of snoRNAs bearing no sequence complementarity to rRNAs or snRNAs (Cavaille et al. 2000). One of these snoRNAs was HBII-52, an RNA bearing all the structural hallmarks of a typical C/D snoRNA that exhibits sequence complementarity to the alternative exon $\mathrm{Vb}$ of the serotonin receptor $5-\mathrm{HT}_{2 \mathrm{C}}$. HBII-52 is expressed from the SNURF-SNRPN locus, localized in the PraderWilli critical region on chromosome 15. This locus appears to be one of the most complex transcriptional units in the human genome (Fig. 1A) (Runte et al. 2001). It spans more than $460 \mathrm{~kb}$ and contains at least 148 exons. Ten exons in the $5^{\prime}$ part of the gene are transcribed into a bicistronic mRNA that encodes the SNURF ( $\mathrm{SmN}$ upstream reading frame) and the $\mathrm{SmN}$ (small RNP in neurons) protein. The locus harbors a bipartite imprinting center (IC) that silences most maternal genes of the Prader-Willi critical region. Due to this imprinting, the SNURF-SNRPN gene is expressed only from the paternal allele. The large $3^{\prime}$ UTR (untranslated region) of the SNURF-SNRPN locus harbors clusters of the C/D box snoRNAs, HBII-85 and HBII-52, that are present in at least 24 and 47 copies, respectively. In addition, the region harbors single copies of other $\mathrm{C} / \mathrm{D}$ box snoRNAs: HBII-13, HBII-436, HBII-437, HBII-438A, and HBII438B. The snoRNAs are flanked by noncoding exons and show a large degree of conservation between mouse and human. In contrast, their flanking, noncoding exons are only poorly conserved. In contrast to the SNURF and $\mathrm{SmN}$ proteins that can be detected in most tissues (Barr et al. 1995), the snoRNAs in this locus show tissuespecific expression, indicating tissue-specific processing of the 3'UTR (Fig. 1B). Expression of HBII-52 could be detected only in brain, whereas other snoRNAs could be found in nonbrain tissues as well. The 47 snoRNAs located in the HBII-52 cluster that exhibit sequence complementarity to exon $\mathrm{Vb}$ of the serotonin receptor $2 \mathrm{C}$ mRNA (Fig. 1C) were analyzed in more detail. The corresponding mouse MBII-52 snoRNAs are expressed throughout the mouse brain. They are most abundant in the hippocampus, but absent in choroid plexus and some thalamic nuclei (Rogelj et al. 2003). The expression of MBII-52 is up-regulated during early memory consolidation in the hippocampus (Rogelj et al. 2003).

\section{PRADER-WILLI SYNDROME}

PWS is a congenital disease with an incidence of about 1 in 8,000-20,000 live births. It is disproportionately more often reported in Caucasians. It is caused by the lack of expression of genes located on chromosome 15q11-q13 that contains the SNURF-SNRPN locus. Since this region is maternally imprinted, most genes expressed are from the father's allele, and loss of their expression causes PWS. PWS shows a biphasic clinical phenotype. In the neonatal period, there is a failure to thrive, indicated by muscle hypotonia, feeding difficulties, and hypogonadism. Later, the patients are characterized by short stature and develop mild to moderate mental retardation, behavioral problems, and hyperphagia that leads to severe obesity. PWS is the most common genetic cause of marked obesity in humans, and consequences from the excess weight, such as type II diabetes, are a major complication (Butler et al. 2006). Children with PWS show low levels of growth hormone, insulin-like growth factor (IGF)-I and insulin, and elevated levels of ghrelin (Eiholzer et al. 1998a,b; Cummings et al. 2002). Subsequently, growth hormone substitution was approved for treatment of children with PWS (Carrel et al. 2006).

Genetic evidence shows that the SNURF-SNRPN locus has a major role in PWS, and its deletion causes PWS-like symptoms in mouse models (Stefan et al. 2005). However, this locus gives rise to only two proteins: SmN and SNURF. Lack of these proteins and of several other proteins (NDN, MAGEL2) located centromeric from the SNURF-SNRPN locus could be ruled out as major contributors to PWS (Ding et al. 2005). It was therefore interesting that the HBII-52 snoRNA located in the 3'UTR of SNURF-SNRPN locus exhibited an 18-nucleotide sequence complementarity to the alternative exon of the serotonin receptor $5-\mathrm{HT}_{2 \mathrm{C}}$.

\section{SEROTONIN RECEPTOR 5-HT $2 \mathrm{C}$}

Serotonin (5-hydroxytryptamine, 5-HT) is a neurotransmitter. It acts on at least 14 different receptors that can be subdivided into seven distinct classes. With the exception of one ligand-gated ion channel, all serotonin receptors are coupled to $\mathrm{G}$ proteins. Alternative premRNA processing largely increases the number of proteins made from these receptors. The serotonergic system 
A
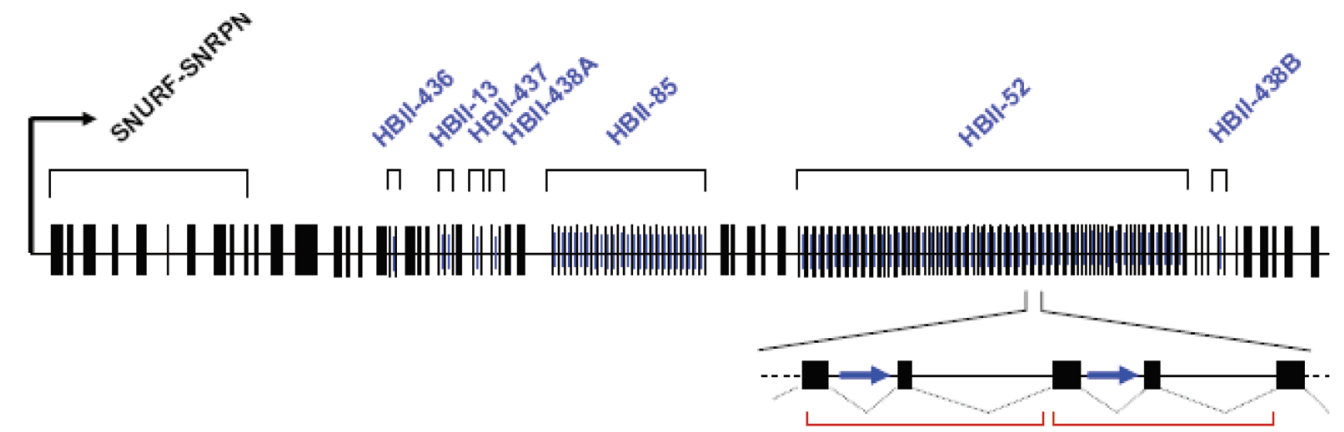

B

\begin{tabular}{|l|l|l|l|l|l|l|l|}
\hline & Brain & Liver & Muscle & Lung & Kidney & Heart & copies \\
\hline HBII-436 & +++ & + & ++ & +++ & ++ & ++ & 1 \\
\hline HBII-13 & ++++ & + & ++ & ++ & ++ & + & 1 \\
\hline HBII-438A/B & ++++ & + & ++ & ++ & ++ & + & 2 \\
\hline HBII-85 & ++++ & - & + & + & ++ & - & 24 \\
\hline HBII-52 & ++++ & - & - & - & - & - & 47 \\
\hline
\end{tabular}

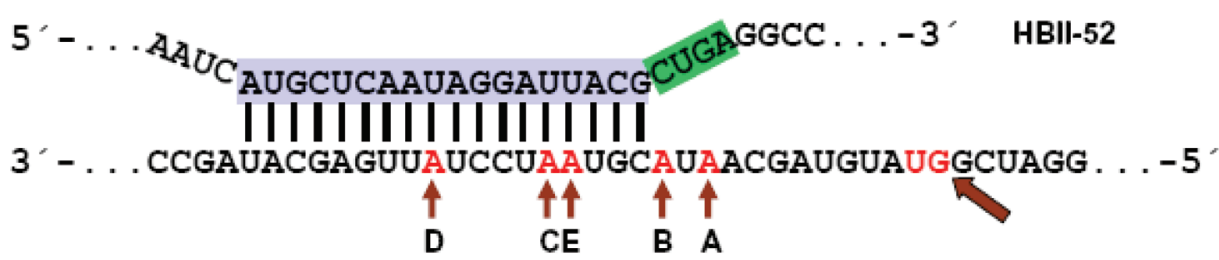

5HT2CR

D

B A MRNA

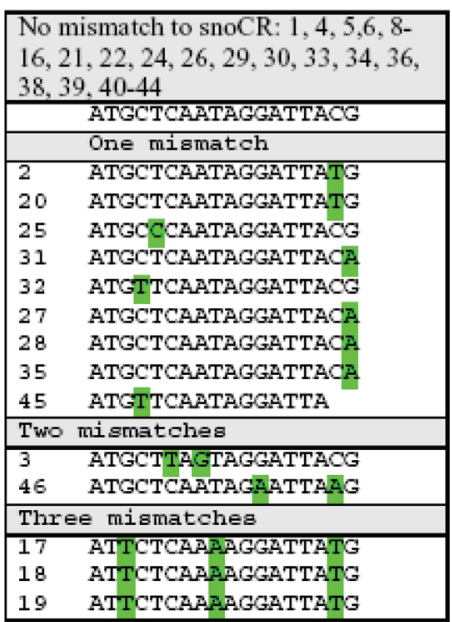

Figure 1. The SNURF-SNRPN locus. (A) Schematic overview of the locus. (Black vertical lines) Exons; (blue vertical lines) snoRNAs. The magnified region shows the arrangement of the snoRNAs (black arrows) between noncoding exons (black boxes). (B) Expression of the snoRNAs found in the locus as determined by RT-PCR and northern blot (Cavaille et al. 2000; Runte et al. 2001). The relative intensity of the snoRNAs in different tissues is indicated by plus (+) signs. (C) Complementarity of the $47 \mathrm{HBII}-$ 52 snoRNAs toward the serotonin receptor $5-\mathrm{HT}_{2 \mathrm{C}}$ exon $\mathrm{Vb}$ sequence. The base complementarity between the antisense box of the human HBII-52 snoRNA and the human 5- $\mathrm{HT}_{2 \mathrm{C}}$ receptor is shown. Arrows indicate the $\mathrm{A} \rightarrow \mathrm{I}$ editing sites $(A-E)$. (Open arrow) Proximal splice site; (green) D box. The table summarizes all human HBII-52 snoRNAs and their complementarity to the 5-HT $2 \mathrm{C}$ exon $\mathrm{Vb}$ sequences. (Green boxes) Mismatches in the complementary regions.

interferes with numerous brain functions, including mood, sleep, sexuality, and appetite. The 5- $\mathrm{HT}_{2 \mathrm{C}}$ (previously named $\left.5-\mathrm{HT}_{1 \mathrm{C}}\right)$ receptor $\left(5-\mathrm{HT}_{2 \mathrm{C}} \mathrm{R}\right)$ belongs to a family of seven-transmembrane-containing G-proteincoupled receptors (GPCRs) and is mapped to human $\mathrm{X}$ chromosome band $\mathrm{q} 24$. $5-\mathrm{HT}_{2 \mathrm{C}} \mathrm{R}$ mRNA is widely expressed in the central nervous system and is developmentally regulated. Mice lacking $5-\mathrm{HT}_{2 \mathrm{C}} \mathrm{R}$ show hyperphagia leading to obesity and develop seizures (Tecott et al. 1995). Through phospholipase-C-generated second messengers, the serotonin $2 \mathrm{C}$ receptor can modulate cyclic AMP accumulation, can regulate $\mathrm{K}^{+}$and $\mathrm{Cl}^{-}$channels, can 
both inhibit and stimulate nitric oxide (NO) levels, and can also regulate mitogenesis (Raymond et al. 2001). In summary, a broad range of psychoactive compounds including appetite suppressant, antidepressant, antipsychotic, anxiolytic, psychostimulant, and psychedelic drugs affect the $5-\mathrm{HT}_{2 \mathrm{C}}$ receptor, demonstrating that the receptor has a physiological role in these processes (Giorgetti and Tecott 2004).

\section{THE SNORNA HBII-52 REGULATES ALTERNATIVE SPLICING OF THE 5-HT ${ }_{2 C}$ RECEPTOR}

The $5-\mathrm{HT}_{2 \mathrm{C}}$ receptor is located on the $\mathrm{X}$ chromosome and undergoes alternative splicing. Only when its alternative exon $\mathrm{Vb}$ is included in the mRNA can a functional receptor be made, since exon $\mathrm{Vb}$ skipping causes a frameshift. Exon $\mathrm{Vb}$ is expressed throughout the brain, but it is mostly absent in the choriod plexus. Exon $\mathrm{Vb}$ is edited on at least five sites by ADAR2-mediated adenosin to inosine deamination. These editing events promote exon $\mathrm{Vb}$ inclusion (Flomen et al. 2004), generating a full-length receptor.

The antisense box of the C/D box snoRNA HBII-52 exhibits an 18-nucleotide, phylogenetically conserved sequence complementarity to the alternative exon $\mathrm{Vb}$ of the $5-\mathrm{HT}_{2 \mathrm{C}}$ receptor. The snoRNA is located on chromosome 15 and is expressed throughout the brain, but it is absent in the choroid plexus, indicating a correlation between HBII-52 expression and exon $\mathrm{Vb}$ usage. We therefore analyzed the influence of HBII-52 on $5-\mathrm{HT}_{2 \mathrm{C}} \mathrm{R}$ pre-mRNA processing and found that HBII-52 promotes usage of exon $\mathrm{Vb}$ (Kishore and Stamm 2006). In vivo, the
HBII-52 snoRNA binds transiently to exon $\mathrm{Vb}$. Exon $\mathrm{Vb}$ contains two splicing silencer sequences that prevent inclusion of the exon in the mRNA (Wang et al. 2004) and it is therefore likely that HBII-52 blocks the action of these silencers (Kishore and Stamm 2006). The identification of these silencing elements in exon $\mathrm{Vb}$ also explains the earlier findings that $\mathrm{A} \rightarrow \mathrm{I}$ editing promotes exon $\mathrm{Vb}$ inclusion (Flomen et al. 2004), since the editing sites are located in the first of the two silencing elements, whose activity is destroyed by $\mathrm{A} \rightarrow \mathrm{I}$ editing (Kishore and Stamm 2006).

Due to the RNA editing, however, the amino acids encoded by exon $\mathrm{Vb}$ are changed. These amino acids are located in the intracellular loop of the receptor that couples to $\mathrm{G}$ proteins. Changing these amino acids through editing generates a receptor with 10-100-fold lower efficacy (Wang et al. 2000). Therefore, the most likely physiological role of the snoRNA HBII-52 is to promote inclusion of exon $\mathrm{Vb}$ of the $5-\mathrm{HT}_{2 \mathrm{C}}$ receptor without the need of the editing that would change the receptor properties. An absence of HBII-52 would therefore reduce the expression of nonedited $5-\mathrm{HT}_{2 \mathrm{C}}$ receptor mRNA. This prediction was tested in brain samples derived from individuals with PWS that do not express the HBII-52 snoRNA. In three of the four major editing sites, a reduction of the nonedited forms was observed. This strongly suggests that the absence of the HBII-52 snoRNA in individuals with PWS causes a misregulation of $5-\mathrm{HT}_{2 \mathrm{C}}$ receptor mRNA isoforms (Fig. 2). Interestingly, some features of the $5-\mathrm{HT}_{2 \mathrm{C}}$ knockout mice, such as hyperphagia and obesity, reflect the clinical presentation of individuals with PWS that lack the HBII-52 snoRNA. So far, HBII-52 was absent in all persons with PWS that were tested.

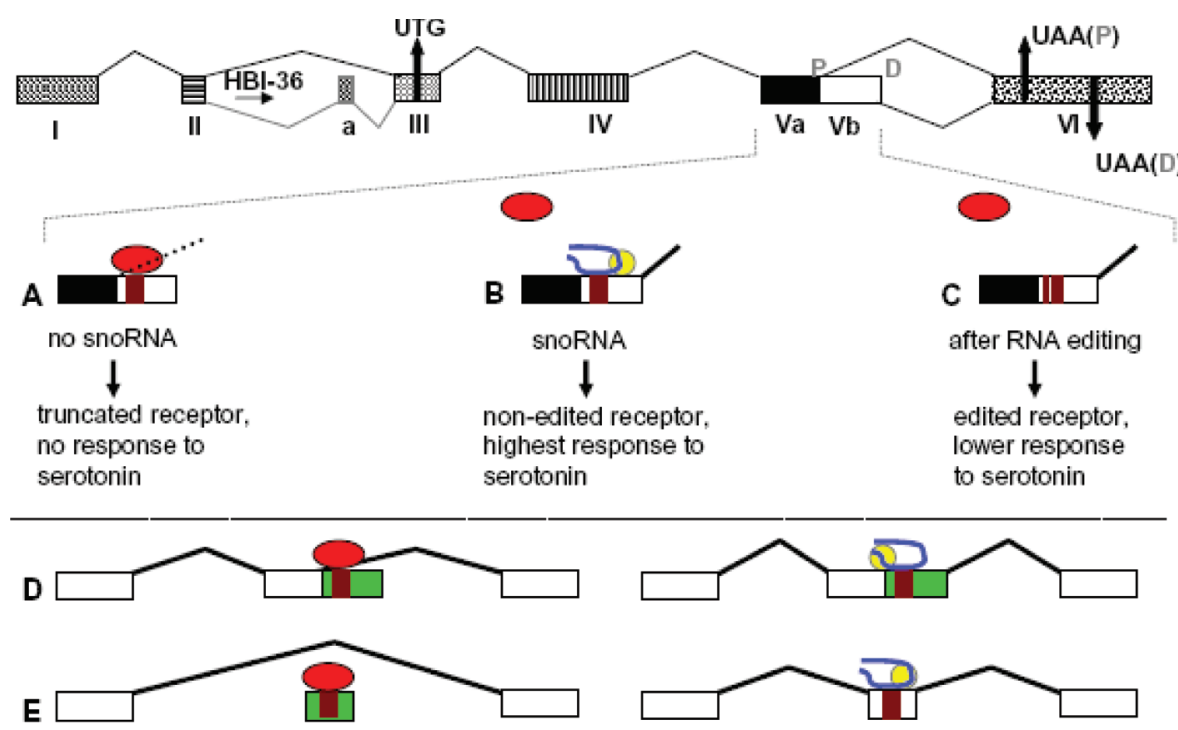

Figure 2. The working model for the influence of the HBII-52 snoRNA on the serotonin receptor. The gene structure of the serotonin receptor is shown in the top line; "a" is a novel exon that we identified. The arrow indicates HBI-36, another H/ACA box snoRNA in the receptor mRNA. $(A-C)$ Regulation of the exon $\mathrm{Vb}$ splice site selection; $(A-C)$ regulation of exon $\mathrm{Vb}$. $(A)$ Exon $\mathrm{Vb}$ contains a silencer (brown box) that prevents its usage, most likely by binding to a trans-acting factor (red circle). (B) snoRNA HBII-52 (blue line) can replace this silencer but needs additional sequence elements, possibly binding to other trans-acting factors (yellow circle). HBII-52 presence results therefore in exon inclusion. (C) Editing mutates this silencer (striped purple box), preventing binding of the trans-acting factor, which leads to exon $\mathrm{Vb}$ inclusion. The effect on the receptor protein is indicated below each scenario. Mechanism $\mathrm{B}$ is missing in patients with PWS. Silencer sequences are found in other genes misregulated in PWS. We hypothesize that in healthy individuals, HBII-52 regulates exons in these messages in a similar fashion $(D, E)$. 
However, two patients were described who lack the paternal HBII-52 snoRNA cluster and suffer from Angelman syndrome, but not PWS (Greger et al. 1993; Burger et al. 2002). It has not been investigated whether these patients express HBII-52, but it is possible that they either express HBII-52 from the maternal allele by an unknown mechanism or that the alternative splicing defects caused by the lack of this snoRNA are modified by a unique composition of splicing regulatory factors in these two patients.

\section{CONCLUSIONS AND PERSPECTIVE}

The results summarized here show that snoRNAs generated by the SNURF-SNRPN locus have a role in gene regulation. They are not transcriptional noise without function. An important open question is whether the regulation of alternative splicing by the HBII-52 snoRNA is a unique, special event or an example of a new regulatory function of snoRNAs. Currently, there are no other messenger or pre-mRNAs that exhibit complete complementarity to antisense elements of snoRNAs. However, a complete complementarity is not necessary in other systems that need binding of different RNAs. The complementartity of U1 snRNA to $5^{\prime}$ splice sites is almost always interrupted, microRNAs show only a short, degenerate complementarity to their targets, and C/D box snoRNAs functioning in ribosomal 2'-O-methylation have nonpaired regions between their antisense boxes and targets. In the HBII-52 cluster, 14 of 47 snoRNAs have between 1 and 3 mismatches toward the exon VB target sequence. If three mismatches toward a target are allowed in the 18 nucleotides of the antisense box of HBII-52, more than 1000 putative target RNAs can be identified. The exact contribution of the snoRNAs located in the SNURFSNRPN locus to the PWS remains to be determined. If the action of these snoRNAs on their RNA targets tolerate mismatches between the target RNA and the snoRNA antisense boxes, they could act as major regulators in RNA processing and could well cause the disease. The identification of their targets and the elucidation of their exact mode of action could therefore lead to the development of new therapeutic strategies for PWS.

\section{ACKNOWLEDGMENTS}

This work was supported by the Deutsche Forschungsgemeinschaft and the BMBF.

\section{REFERENCES}

Barr J.A., Jones J., Glenister P.H., and Cattanach B.M. 1995. Ubiquitous expression and imprinting of Snrpn in the mouse. Mamm. Genome 6: 405.

Burger J., Horn D., Tonnies H., Neitzel H., and Reis A. 2002. Familial interstitial $570 \mathrm{kbp}$ deletion of the UBE3A gene region causing Angelman syndrome but not Prader-Willi syndrome. Am. J. Med. Genet. 111: 233.

Butler M.G., Hanchett J.M., and Thompson T.E. 2006. Clinical findings and natural history of Prader-Willi syndrome. In Management of Prader-Willi syndrome (ed. M.G. Butler et al.), p. 3. Springer, New York.

Carninci P., Kasukawa T., Katayama S., Gough J., Frith M.C., Maeda N., Oyama R., Ravasi T., Lenhard B., Wells C., et al.
2005. The transcriptional landscape of the mammalian genome. Science 309: 1559.

Carrel A.L., Lee P.D.K., and Mogul H.R. 2006. Growth hormone and Prader-Willi syndrome. In Management of PraderWilli syndrome (ed. M.G. Butler et al.), p. 201. Springer, New York.

Cavaille J., Buiting K., Kiefmann M., Lalande M., Brannan C.I., Horsthemke B., Bachellerie J.P., Brosius J., and Hüttenhofer A. 2000. Identification of brain-specific and imprinted small nucleolar RNA genes exhibiting an unusual genomic organization. Proc. Natl. Acad. Sci. 97: 14311.

Celotto A.M. and Graveley B.R. 2001. Alternative splicing of the Drosophila Dscam pre-mRNA is both temporally and spatially regulated. Genetics 159: 599.

Cheng J., Kapranov P., Drenkow J., Dike S., Brubaker S., Patel S., Long J., Stern D., Tammana H., Helt G., et al. 2005. Transcriptional maps of 10 human chromosomes at 5nucleotide resolution. Science 308: 1149.

Cummings D.E., Clement K., Purnell J.Q., Vaisse C., Foster K.E., Frayo R.S., Schwartz M.W., Basdevant A., and Weigle D.S. 2002. Elevated plasma ghrelin levels in Prader Willi syndrome. Nat. Med. 8: 643 .

Ding F., Prints Y., Dhar M.S., Johnson D.K., GarnachoMontero C., Nicholls R.D., and Francke U. 2005. Lack of Pwcr1/MBII-85 snoRNA is critical for neonatal lethality in Prader-Willi syndrome mouse models. Mamm. Genome 16: 424

Eiholzer U., Stutz K., Weinmann C., Torresani T., Molinari L., and Prader A. 1998a. Low insulin, IGF-I and IGFBP-3 levels in children with Prader-Labhart-Willi syndrome. Eur. J. Pediatr. 157: 890.

Eiholzer U., Gisin R., Weinmann C., Kriemler S., Steinert H., Torresani T., Zachmann M., and Prader A. 1998b. Treatment with human growth hormone in patients with Prader-LabhartWilli syndrome reduces body fat and increases muscle mass and physical performance. Eur. J. Pediatr. 157: 368.

Filipowicz W. and Pogacic V. 2002. Biogenesis of small nucleolar ribonucleoproteins. Curr. Opin. Cell Biol. 14: 319.

Flomen R., Knight J., Sham P., Kerwin R., and Makoff A. 2004. Evidence that RNA editing modulates splice site selection in the 5-HT2C receptor gene. Nucleic Acids Res. 32: 2113.

Giorgetti M. and Tecott L.H. 2004. Contributions of 5-HT(2C) receptors to multiple actions of central serotonin systems. Eur. J. Pharmacol. 488: 1.

Greger V., Woolf E., and Lalande M. 1993. Cloning of the breakpoints of a submicroscopic deletion in an Angelman syndrome patient. Hum. Mol. Genet. 2: 921.

Kampa D., Cheng J., Kapranov P., Yamanaka M., Brubaker S., Cawley S., Drenkow J., Piccolboni A., Bekiranov S., Helt G., et al. 2004. Novel RNAs identified from an in-depth analysis of the transcriptome of human chromosomes 21 and 22. Genome Res. 14: 331.

Kishore S. and Stamm S. 2006. The snoRNA HBII-52 regulates alternative splicing of the serotonin receptor $2 \mathrm{C}$. Science 311: 230.

Lewis B.P., Green R.E., and Brenner S.E. 2003. Evidence for the widespread coupling of alternative splicing and nonsensemediated mRNA decay in humans. Proc. Natl. Acad. Sci. 100: 189 .

Missler M. and Sudhof T.C. 1998. Neurexins: Three genes and 1001 products. Trends Genet. 14: 20.

Pan Q., Shai O., Misquitta C., Zhang W., Saltzman A.L., Mohammad N., Babak T., Siu H., Hughes T.R., Morris Q.D., et al. 2004. Revealing global regulatory features of mammalian alternative splicing using a quantitative microarray platform. Mol. Cell 16: 929.

Raymond J.R., Mukhin Y.V., Gelasco A., Turner J., Collinsworth G., Gettys T.W., Grewal J.S., and Garnovskaya M.N. 2001. Multiplicity of mechanisms of serotonin receptor signal transduction. Pharmacol. Ther. 92: 179.

Rogelj B., Hartmann C.E., Yeo C.H., Hunt S.P., and Giese K.P. 2003. Contextual fear conditioning regulates the expression of brain-specific small nucleolar RNAs in hippocampus. Eur. J. Neurosci. 18: 3089 
Runte M., Hüttenhofer A., Gross S., Kiefmann M., Horsthemke B., and Buiting K. 2001. The IC-SNURF-SNRPN transcript serves as a host for multiple small nucleolar RNA species and as an antisense RNA for UBE3A. Hum. Mol. Genet. 10: 2687.

Sanford J.R., Gray N.K., Beckmann K., and Caceres J.F. 2004. A novel role for shuttling SR proteins in mRNA translation. Genes Dev. 18: 755 .

Stamm S., Zhu J., Nakai K., Stoilov P., Stoss O., and Zhang M.Q. 2000. An alternative-exon database and its statistical analysis. DNA Cell Biol. 19: 739.

Stamm S., Ben-Ari S., Rafalska I., Tang Y., Zhang Z., Toiber D., Thanaraj T.A., and Soreq H. 2005. Function of alternative splicing. Gene 344: 1.

Stefan M., Ji H., Simmons R.A., Cummings D.E., Ahima R.S., Friedman M.I., and Nicholls R.D. 2005. Hormonal and metabolic defects in a Prader-Willi syndrome mouse model with neonatal failure to thrive. Endocrinology 146: 4377.
Steitz J.A. and Tycowski K.T. 1995. Small RNA chaperones for ribosome biogenesis. Science 270: 1626.

Tecott L.H., Sun L.M., Akana S.F., Strack A.M., Lowenstein D.H., Dallman M.F., and Julius D. 1995. Eating disorder and epilepsy in mice lacking 5-HT2c serotonin receptors. Nature 374: 542 .

Wang Q., O’Brien P.J., Chen C.-X., Cho D.-S.C., Murray J.M., and Nishikura K. 2000. Altered G protein-coupling functions of RNA editing isoform and splicing variant serotonin $2 \mathrm{C}$ receptors. J. Neurochem. 74: 1290.

Wang Z., Rolish M.E., Yeo G., Tung V., Mawson M., and Burge C.B. 2004. Systematic identification and analysis of exonic splicing silencers. Cell 119: 831.

Watkins N.J., Segault V., Charpentier B., Nottrott S., Fabrizio P., Bachi A., Wilm M., Rosbash M., Branlant C., and Luhrmann R. 2000. A common core RNP structure shared between the small nucleolar box C/D RNPs and the spliceosomal U4 snRNP. Cell 103: 457. 


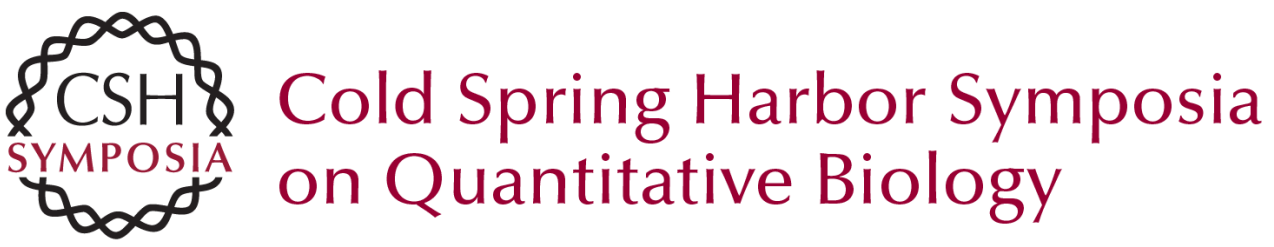

\section{Regulation of Alternative Splicing by snoRNAs}

S. KISHORE and S. STAMM

Cold Spring Harb Symp Quant Biol 2006 71: 329-334

Access the most recent version at doi:10.1101/sqb.2006.71.024

References This article cites 31 articles, 9 of which can be accessed free at: http://symposium.cshlp.org/content/71/329.full.html\#ref-list-1

\section{License}

Email Alerting Receive free email alerts when new articles cite this article - sign up in Service the box at the top right corner of the article or click here. 